\title{
Analysis of Hospital Mortality and Epidemiology in Trauma Patients: A Multi-Center Study
}

\author{
Ozgur Sogut ${ }^{\mathrm{a}, \mathrm{h}}$, Mustafa Burak Sayhan ${ }^{\mathrm{b}}$, Mehmet Tahir Gokdemir ${ }^{\mathrm{a}}$, Mehmet Emin Boleken ${ }^{\mathrm{c}}$, \\ Behcet Al ${ }^{\mathrm{d}}$, Rustu Kose ${ }^{\mathrm{e}}$, Abdullah Ozgonul ${ }^{\mathrm{f}}$, Hanife Pinar Kara ${ }^{\mathrm{g}}$
}

\begin{abstract}
Background: This study evaluated the clinical characteristics of trauma patients in the southeastern coastal area of Turkey and investigated the factors influencing mortality.

Methods: Patients admitted with trauma to the emergency departments of Harran and Gaziantep Medical Schools and to the emergency services of hospitals in Sanliurfa between June 2008 and December 2008 were enrolled retrospectively in this study. All medical records and follow-up data were reviewed for each patient.

Results: The study evaluated 15,120 trauma patients. The causes of trauma were motor vehicle accidents $(38.7 \%)$, falls from heights (36.8\%), burns $(7.8 \%)$, knife wounds and gun shots $(8.1 \%)$, homicides $(6.5 \%)$, and workplace-related accidents $(2.1 \%)$. The overall patient mortality rate was $3.8 \%$. The mean patient ages were 47.8 \pm 0.9 and $29.7 \pm 0.4$ among those who died and among those who survived, respectively $(\mathrm{P}<0.01)$. The median times to arrival were 130 minutes and 42 minutes among those who died and among
\end{abstract}

Manuscript accepted for publication August 23, 2011

${ }^{\mathrm{a}}$ Department of Emergency Medicine, Harran University, School of Medicine, Sanliurfa, Turkey

${ }^{b}$ Department of Emergency Medicine, Trakya University, School of Medicine, Edirne, Turkey

${ }^{c}$ Department of Pediatric Surgery, Harran University, School of Medicine, Sanliurfa, Turkey

${ }^{\mathrm{d}}$ Department of Emergency Medicine, Gaziantep University, School of Medicine, Sanliurfa, Turkey

e Department of Plastic and Reconstructive Surgery, Rize University, School of Medicine, Rize, Turkey

fDepartment of General Surgery, Harran University, School of Medicine, Sanliurfa, Turkey

${ }^{g}$ Department of Emergency Medicine, Sanliurfa Research and Training Hospital, Sanliurfa, Turkey

${ }^{\mathrm{h}}$ Corresponding author: Ozgur Sogut, Harran Universitesi Tip

Fakultesi, Acil Tip Anabilim Dali, Morfoloji Binasi, Yenisehir Kampusu,

TR-63300, Sanliurfa, Turkey. Email: drosogut@harran.edu.tr

doi:10.4021/jcs101e those who survived, respectively $(\mathrm{P}<0.01)$. Whereas $79.9 \%$ of patients were discharged after treatment in the emergency departments, $16.3 \%$ were referred to various departments for hospitalization, and $3.8 \%$ were admitted to the intensive care unit (ICU). The mean score on the Glasgow Coma Scale was $7.5 \pm 0.3$ among who died and $12.8 \pm 0.6$ among those who survived $(\mathrm{P}<0.05)$, and the mean Revised Trauma Scores were $8.7 \pm 0.5$ among those who died and $11.5 \pm 0.7$ among those who survived $(\mathrm{P}<0.05)$. Intubation or cardiopulmonary resuscitation was initiated in $88 \%$ of those who died and $43.5 \%$ of those who survived $(\mathrm{P}<0.05)$. Of those who died, $84 \%$ had cranial injuries and $43.5 \%$ had thoracic injuries.

Conclusions: Frequent causes of trauma in our region are motor vehicle accidents and falls from heights. Type of trauma, rapid arrival at the hospital, hospital procedures and interventions, age, sex, and trauma scores were predictors of mortality in trauma patients.

Keywords: Trauma; Mortality; Epidemiology; Emergency department

\section{Introduction}

Many trauma patients are admitted through emergency departments every day. Trauma remains the most frequent cause of mortality in young people (aged 1 - 44 years) worldwide [1]. Because $81.8 \%$ of the population of Turkey is young, it is important to know how to manage trauma patients in this country [2]. Patients older than 60 who have suffered trauma in motor vehicle accidents and those with craniocerebral, thoracic, or abdominal injuries are at higher risk of in-hospital mortality [3]. Appropriate interventions and rapid transportation of the patients from the site of trauma can prevent mortality and morbidity $[4,5]$. This study examined the clinical characteristics and factors influencing mortality in trauma patients in the southeastern coastal region of Turkey.

\section{Materials and Methods}

This retrospective observational registry study used trauma registry data from the emergency departments (EDs) of 
Table 1. Demographic Characteristics and Types of Injury Among 15,120 Trauma Patients

\begin{tabular}{|c|c|c|}
\hline Data category & & n (\%) \\
\hline \multirow{2}{*}{ Sex } & Male & $10269(67.9)$ \\
\hline & Female & $4851(32.1)$ \\
\hline \multirow{6}{*}{ Age Group (yea } & $0-15$ & $977(26.3)$ \\
\hline & $16-29$ & $3049(20.1)$ \\
\hline & $30-44$ & $5665(37.4)$ \\
\hline & $45-59$ & $1607(10.75)$ \\
\hline & $60-74$ & $723(4.8)$ \\
\hline & $>75$ & $99(0.65)$ \\
\hline \multirow{6}{*}{ Injury mechanis } & Motor vehicle accidents & $5851(38.7)$ \\
\hline & Falls & $5564(36.8)$ \\
\hline & Burns & $1179(7.8)$ \\
\hline & Knife wounds and gun shots & $1224(8.1)$ \\
\hline & Homicides & $982(6.5)$ \\
\hline & Workplace-related accidents & $317(2.1)$ \\
\hline \multirow{2}{*}{ Injury severity } & $\operatorname{GCS}(0-15)$ & $13 \pm 0.6$ \\
\hline & RTS $(0-12)$ & $9 \pm 0.4$ \\
\hline \multirow{6}{*}{ Injury type } & Craniocerebral injury & 7405 (49) \\
\hline & Extremity injury & $5413(35.8)$ \\
\hline & Thoracic injury & $4491(29.7)$ \\
\hline & Abdominal injury & $2661(17.6)$ \\
\hline & Pelvic injury & $1633(10.8)$ \\
\hline & Spinal cord injury & $1542(10.2)$ \\
\hline \multirow{2}{*}{ Outcome } & Death & $575(3.8)$ \\
\hline & Survival & $14,545(96.2)$ \\
\hline
\end{tabular}

Data presented as numbers (\%) of patients. GCS, Glasgow Coma Scale; RTS, Revised Trauma Score.

Harran and Gaziantep Medical Schools and from the emergency services of hospitals in Sanliurfa collected between June 2008 and December 2008. These four centers provide 24-hour trauma services and receive both direct admissions and transfers from affiliated district hospitals. The registry included all trauma patients sustaining potentially severe injuries during the 6 months under study who warranted an initial evaluation or resuscitation in a trauma resuscitation 
Table 2. Surviving and Non-Surviving Patients According to Sex and Route of Admission to Hospital

\begin{tabular}{|c|c|c|c|c|c|}
\hline \multicolumn{2}{|l|}{ Characteristics } & \multirow{2}{*}{$\begin{array}{c}\begin{array}{c}\text { Survivors } \\
\text { (n) }\end{array} \\
9782\end{array}$} & \multirow{2}{*}{$\begin{array}{c}\begin{array}{c}\text { Non-Survivors } \\
\text { (n) }\end{array} \\
487\end{array}$} & \multirow{2}{*}{$\begin{array}{l}\begin{array}{c}\text { Total } \\
\text { (n) }\end{array} \\
10269\end{array}$} & \multirow{2}{*}{$\begin{array}{r}\begin{array}{r}\text { Mortality } \\
(\%)\end{array} \\
4.7\end{array}$} \\
\hline & Male & & & & \\
\hline \multicolumn{6}{|l|}{ Sex } \\
\hline & Female & 4763 & 88 & 4851 & 1.8 \\
\hline \multirow{3}{*}{$\begin{array}{l}\text { Admission to } \\
\text { hospital }\end{array}$} & ICU & 226 & 349 & 575 & 60.7 \\
\hline & $\begin{array}{l}\text { Various } \\
\text { departments }\end{array}$ & 2280 & 184 & 2464 & 7.5 \\
\hline & $\begin{array}{l}\text { Emergency } \\
\text { department }\end{array}$ & 12039 & 42 & 12081 & 0.3 \\
\hline
\end{tabular}

Data presented as numbers (\%) of patients. ICU, Intensive Care Unit; Various departments, Neurosurgery, Orthopedics, General Surgery, Pediatric Surgery, Plastic and Reconstructive Surgery, Urology.

room, including patients with unstable vital signs or suspected severe injuries. The clinical management of these patients followed a multidisciplinary approach and Advanced Trauma Life Support (ATLS) principles. The age, sex, mechanism of trauma, time of trauma, type of trauma, mode of transportation, time to hospital admission, procedures or interventions, Glasgow Coma Scale (GCS) scores, Revised Trauma Scores (RTS), length of hospital stay, and mortality rates were analyzed in terms of patient outcomes.

The statistical analyses were performed using SPSS v15.0 (SPSS, Chicago, IL, USA). Intragroup comparisons (survivors vs. non-survivors) were performed using the Mann-Whitney $U$-test and $\chi 2$ test. Data are presented as the means \pm SEs (standard errors of the mean), with significance set at $\mathrm{P}<0.05$.

\section{Results}

\section{Demographic and clinical characteristics of trauma pa- tients}

Approximately 140,000 patients were admitted to the ED during the 6-month study period. Of these, we evaluated $15,120(10.8 \%)$ who had experienced trauma. The majority $(67.9 \%)$ of patients were male, and the median patient age was $36.8 \pm 0.7$ (range: 4 - 84) years. Adults and children constituted $73.7 \%$ and $26.3 \%$ of the patients, respectively. Those 30 - 44 years of age accounted for a plurality (37.4\%) of all trauma cases. The median time to arrival was 45 minutes. Motor vehicle accidents (MVAs) were the most common cause of admission to the ED and accounted for $38.7 \%$ of all trauma admissions; falls were the second most common cause of admission, accounting for $36.8 \%$ of the cases. Other causes of trauma-related admissions to the ED were knife wounds and gun shots $(8.1 \%)$, burns $(7.8 \%)$, homicides $(6.5 \%)$, and workplace-related accidents $(2.1 \%)$. The mean GCS and RTS scores were $13 \pm 0.6$ and $9 \pm 0.4$, respectively.

Craniocerebral injuries $(49 \%, \mathrm{n}=7405)$ were the most common injury, followed by extremity $(35.8 \%, \mathrm{n}=5413)$, thoracic $(29.7 \%, \mathrm{n}=4491)$, abdominal $(17.6 \%, \mathrm{n}=2661)$, pelvic $(10.8 \%, \mathrm{n}=1633)$, and spinal cord $(10.2 \%, \mathrm{n}=1542)$ injuries. Although $79.9 \%$ of the cases $(n=12,081)$ were discharged after treatment in the ED, $16.3 \%(n=2,464)$ were referred to various departments for hospitalization, and $3.8 \%$ $(\mathrm{n}=575)$ were admitted to the intensive care unit (ICU). The most common departments for admission were neurosurgery and orthopedics. The mean lengths of stay in the ICU and clinics were $14.7 \pm 0.6$ and $9.4 \pm 0.8$ days, respectively.

Motor vehicle accidents were the most common cause of admission to the ICU and accounted for $47 \%$ of traumarelated admissions to the ICU; falls were the second most common cause, accounting for $29 \%$ of such admissions. Additional causes of trauma-related admission to the ICU were homicides, knife wounds, gun shots, burns, and other types of injuries. The demographic characteristics of patients and the types of trauma are summarized in Table 1.

\section{Demographic and clinical characteristics of patients who died}

The overall mortality rate was $3.8 \%(n=575)$; the mortality rate was $4.7 \%(\mathrm{n}=487)$ in males and $1.8 \%(\mathrm{n}=88)$ in females $(\mathrm{P}=0.005)$. The median age of those who died was $47.8 \pm 0.9$ and that of those who survived was $29.7 \pm 0.4$ years $(\mathrm{P}=0.008)$. The mortality rate increased with age and 
Table 3. Predictors of Trauma-Related Death in Patients

\begin{tabular}{llcl}
\hline Predictors of Mortality & Non-survivors & Survivors & $\begin{array}{c}\text { Statistical } \\
\text { significance }\end{array}$ \\
\hline Age & & & $<0.01$ \\
Sex (male/female) & $47.8 \pm 0.9$ & $29.7 \pm 0.4$ & $<0.01$ \\
RTS & $487 / 88$ & $9782 / 4763$ & $<0.05$ \\
GCS & $8.7 \pm 0.5$ & $11.5 \pm 0.7$ & $<0.05$ \\
Craniocerebral injury & $7.5 \pm 0.3$ & $12.8 \pm 0.6$ & $<0.01$ \\
Thoracic injury & $84 \%$ & $42.2 \%$ & $<0.01$ \\
Arrival to the hospital (min) & $43.5 \%$ & $21 \%$ & $<0.01$ \\
Hospital procedures & 130 & 42 & $<0.05$ \\
(intubation and /or CPR) & $88 \%$ & $43.5 \%$ & \\
\hline
\end{tabular}

Data are presented as the means \pm SEs or numbers (\%) of patients. ${ }^{a}$ Chi-square test (age, sex), ${ }^{b}$ Mann-Whitney U-test. RTS, Revised Trauma Score; GCS, Glasgow Coma Scale; CPR, Cardiopulmonary resuscitation.

was $25.6 \%, 27.9 \%, 31.4 \%, 44.8 \%, 60.2 \%$, and $71.3 \%$ for those $0-15,16-29,30-44,45-59,60-74$, and $\geq 75$ years of age, respectively.

The median time to hospital arrival was 130 minutes among those who did and 42 minutes among those who survived $(\mathrm{P}=0.003)$; the mean GCS score was $7.5 \pm 0.3$ among those who died and $12.8 \pm 0.6$ among those who survived ( $\mathrm{P}$ $=0.026)$; and the mean RTS score was $8.7 \pm 0.5$ among those who died and $11.5 \pm 0.7$ among those survived $(\mathrm{P}=0.038)$. Mortality occurred most frequently in the ICU $(60.7 \%, \mathrm{n}=$ $349)$, whereas the mortality rate was $7.5 \%(n=184)$ at various departments. A small proportion of patients $(0.34 \%, \mathrm{n}=$ $42)$ died in the ED $(\mathrm{P}=0.007)$. Of those who died, $84 \%$ had cranial injuries $(\mathrm{P}=0.003)$ and $43.5 \%$ had thoracic injuries $(\mathrm{P}=0.006)$. Hospital procedures or interventions (e.g., intubation or cardiopulmonary resuscitation) were performed on $88 \%$ of those who died and on $43.5 \%$ of the survivors ( $\mathrm{P}=$ $0.029)$. Survival and mortality according to sex and hospital admission were presented in Table 2. Predictors of traumarelated death were summarized in Table 3.

\section{Discussion}

Injuries are a major and preventable public health problem in terms of morbidity, premature mortality, or disability. About 5.8 million people worldwide die annually from injuries, and the projections for 2020 show that 8.4 million deaths are expected annually [6,7]. The ED plays a vital role in managing injuries. Trauma requires an immediate and precise diagnosis [8] and is a significant problem in southeastern Turkey. According to our data, $10.8 \%$ of the 140,000 patients admitted to the ED during the 6-month study period had suffered trauma. Most injuries were suffered by those 16 - 44 years of age (57.6\%), especially those $30-44$ years of age $(37.46 \%)$. By contrast, patients $>$ 75 years of age accounted for only $0.65 \%$ of all admissions. Similar findings have been reported by other studies [9-11]. It is also clear that the involvement of those $16-44$ years of age, the most productive group in society, in trauma-related injuries constitutes a huge economic loss to the country.

The preponderance of males among those injured is consistent with data from the World Health Organization (WHO) and the studies conducted by Ghaffar et al. [12], Mock et al. [13], and Moshiro et al. [14]. Similar to other findings, more males than females suffered from all types of injuries; our study identified 10,262 (67.9\%) injured males and 4851 (32.1\%) injured females.

Motor vehicle accidents are among the 10 leading causes of death and disability worldwide and have emerged as a serious public health concern [15]. According to a literature review, falls from heights were the most common cause of admission to the ED and the fourth leading cause of trauma-related death [16]. Additionally, falls from heights are a preventable health problem among adults [17]. In our study, MVAs were the most common cause of admission to the ED, and falls were the second most common cause. To ensure a safe environment, continuing health education programs focused on injury and prevention should be directed at parents and children, and legal measures to prevent injuries should be enacted.

The first 60 minutes after trauma is called the "golden hour" [18]. In our study, the median time to hospital arrival was 45 minutes: 130 minutes among those who died and 42 minutes among the survivors. We suggest that the hospital mortality rate for trauma-related patients has dropped be- 
cause of the early administration of appropriate treatment. According to the WHO data for 2000, an estimated 5.2 million injury-related deaths occurred worldwide, comprising almost $9 \%$ of all deaths [19].

Most studies in which data have been analyzed according to sex have shown that both fatal and nonfatal injuries occurred more frequently among males than females [20, 21]. The overall mortality rate in our study was $3.8 \%$, similar to that reported by Murray et al. [22] and close to the $4 \%$ reported by Bulut et al. [16] and the 2\% reported by Meller and Shermeta [23]. According to our data, the ratio of the mortality among males to that among females was 2:7.

Tan et al. [24] demonstrated that increasing age was a risk factor for mortality after trauma. We also found that the mortality rate increased with age and identified the highest mortality rate (71.3\%) among those 75 years and older and the lowest mortality rate $(25.6 \%)$ among those 0 - 15 years of age. In our study, the mean age of those who died was $47.8 \pm 0.9$ years, and the mean age of those who survived was $29.7 \pm 0.4$.

Several studies have reported that the head region was the most commonly injured in the body [16, 25]. Bulut et al . [16] reported that injuries to the extremities were the second most common injury and that pelvic and vertebral injuries were seen less frequently. In our study, craniocerebral injuries were the most common type of injury, comprising $49 \%$ of injuries. Injuries to the extremities were the second most common injury, comprising $35.8 \%$ of injuries. Pelvic and spinal cord injuries were rather rare $(10.8 \%$ and $10.2 \%$, respectively). Head and thoracic injuries were related to significant rates of mortality $(84 \%)$ in our study, and most of these involved severe craniocerebral injuries. The incidence of thoracic injuries was $43.5 \%$ among those who died and 21\% among those who survived. Agalar et al. [26] found significant relationships between mortality and the Injury Severity Score (ISS), age, and RTS. In our study, the mean RTS and GCS score were significantly lower in nonsurvivors (both comparisons, $\mathrm{P}<0.05$ ) than survivors.

\section{Conclusion}

Hospital emergency-department-based injury registries are very useful in epidemiological studies of injuries. Frequent causes of trauma in our region are traffic accidents and falls from heights. Type of trauma, mechanisms of trauma, rapid arrival at the hospital, hospital procedures or interventions, age, and trauma scores can be used to predict mortality in trauma patients. The majority of trauma patients who present to the ED are treated at this location. Thus, observations in the ED may reveal details of injuries and demographic characteristics and can contribute to the prevention of mortality-related trauma and the development of more organized systems of trauma care.

\section{References}

1. Davis JH, Pruitt JH, Pruitt BA Jr. History. In: Mattox KL, Feliciano DV, Moore EE, editors. Trauma 4th ed. New York McGraw Hill; 2000. p. 3-19.

2. Adas G, Sarvan F, Küpelioglu R, Taviloglu K. Evaluation the trauma and emergency surgery care in three hospitals with different standards in Istanbul. Ulus Travma Derg 1998;4:95-100.

3. Markogiannakis H, Sanidas E, Messaris E, Koutentakis D, Alpantaki K, Kafetzakis A, Tsiftsis D. Predictors of in-hospital mortality of trauma patients injured in vehicle accidents. Ulus Travma Acil Cerrahi Derg. 2008;14(2):125-131.

4. Clark DE, Ryan LM. Concurrent prediction of hospital mortality and length of stay from risk factors on admission. Health Serv Res. 2002;37(3):631-645.

5. Engelhardt S, Hoyt D, Coimbra R, Fortlage D, Holbrook $\mathrm{T}$. The 15-year evolution of an urban trauma center: what does the future hold for the trauma surgeon? J Trauma. 2001;51(4):633-637; discussion 637-638.

6. Krug EG, Sharma GK, Lozano R. The global burden of injuries. Am J Public Health. 2000;90(4):523-526.

7. Murray CJ, Lopez AD. Alternative projections of mortality and disability by cause 1990-2020: Global Burden of Disease Study. Lancet. 1997;349(9064):1498-1504.

8. Yazkan R, Ozsoy IE. Adult, Isolated Chest Injuries Caused by Falls From Roofs in and Around the City of Sanliurfa. JAEM 2010;9:155-157.

9. Gururaj G. Injuries in India: A national perspective. In, Background Papers: Burden of Disease. New Delhi: The National Commission on Macroeconomics and Health, Ministry of Health and Family Welfare, 2005:325-347.

10. Demircan A, Keles A. Forensic emergency medicine6-year experience of 13,823 cases in a university emergency department. Turk J Med Sci 2008;38(6):567-575.

11. Mishra B, Sinha Mishra ND, Sukhla S, Sinha A. Epidemiological study of road traffic accident cases from Western Nepal. Indian J Community Med. 2010;35(1):115121.

12. Ghaffar A, Hyder AA, Masud TI. The burden of road traffic injuries in developing countries: the 1st national injury survey of Pakistan. Public Health. 2004;118(3):211217.

13. Mock CN, Abantanga F, Cumming P, Koepsell TD. Incidence and outcome of injury in Ghana: a communitybased survey. Bull WHO 1997;77(12):955-964.

14. Moshiro C, Heuch I, Astrom AN, Setel P, Hemed Y, Kvale G. Injury morbidity in an urban and a rural area in Tanzania: an epidemiological survey. BMC Public Health. 2005;5:11.

15. Mathers CD, Loncar D. Projections of global mortality and burden of disease from 2002 to 2030. PLoS Med. 2006;3(11):e442. 
16. Bulut M, Koksal O, Korkmaz A, Turan M, Ozguc H. Childhood falls: characteristics, outcome, and comparison of the Injury Severity Score and New Injury Severity Score. Emerg Med J. 2006;23(7):540-545.

17. Lallier M, Bouchard S, St-Vil D, Dupont J, Tucci M. Falls from heights among children: a retrospective review. J Pediatr Surg. 1999;34(7):1060-1063.

18. Newgard CD, Schmicker RH, Hedges JR, Trickett JP, Davis DP, Bulger EM, Aufderheide TP, et al. Emergency medical services intervals and survival in trauma: assessment of the "golden hour" in a North American prospective cohort. Ann Emerg Med. 2010;55(3):235-246 e234.

19. WHO. Preventing Injuries and Violence. A Guide for Ministries of Health. Geneva: World Health Organization; 2007, pp. 6-9.

20. Gorman DR, Ramsay LJ, Wilson GS, Freeland P. Using routine accident and emergency department data to describe local injury epidemiology. Public Health. 1999;113(6):285-289.
21. Sahlin Y, Stene TM, Lereim I, Balstad P. Occurrence of injuries in a defined population. Injury. 1990;21(3):155157.

22. Murray JA, Chen D, Velmahos GC, Alo K, Belzberg $\mathrm{H}$, Asensio JA, Demetriades D, et al. Pediatric falls: is height a predictor of injury and outcome? Am Surg. 2000;66(9):863-865.

23. Meller JL, Shermeta DW. Falls in urban children. A problem revisited. Am J Dis Child. 1987;141(12):12711275.

24. Tan WT, Choy JM, Foo JM. A 5-year profile of trauma admissions to the surgical intensive care unit of a tertiary hospital in Singapore. Ann Acad Med Singapore. 2010;39(5):363-367.

25. Cassidy LD, Potoka DA, Adelson PD, Ford HR. Development of a novel method to predict disability after head trauma in children. J Pediatr Surg. 2003;38(3):482-485.

26. Agalar F, Cakmakci M, Sayek I. Factors effecting mortality in urban vertical free falls: evaluation of 180 cases. Int Surg. 1999;84(3):271-274. 